\title{
Review on Liaoning Daily Open Letter from Critical Thinking Viewpoint
}

\author{
Haowen FENG \& Weimin OUYANG \\ Shanghai University of Political Science and Law, Shanghai, China
}

\begin{abstract}
On November 14, 2014, Liaoning Daily newspaper launched a open letter,whose title was 'Teachers, please do not talk about China like that: An open letter to philosophy and social science teachers'. The open letter This letter sparked much discussion among supporters and opponents.Most of the discussion are emotional more than rational. This paper has no intention to explore any reasons behind, but only to apply critical thinking to analyze various thinking fallacies committed by the letter.
\end{abstract}

KEYWORD: Critical Thinking; Logic; Thinking Fallacy

\section{INTRODUCTION}

On November 14, 2014, Liaoning Daily newspaper launched a special topic named as 'China in university classes'. The first issue of the topic was 'Teachers, please do not talk about China like that: An open letter to philosophy and social science teachers' (hereinafter referred to as the open letter)[1]. The newspaper editorial office claimed that they sent many journalists to attend nearly one hundred lectures in above twenty universities across China for half a month.

According to their lecture notes of 130 thousand words, Liaoning Daily editors summarized three major phenomena:lack of theory identity,lack of political identity and lack of emotion recognition.

Based on the above phenomena, the newspaper then proposed three suggestions: China in university classes should be a clear background, overall view and bright future.

The author would like to believe that the open letter wish philosophy and social science teachers should treat china in a comprehensive, objective and rational manner, whose original intention may be good. However, once the open letter was published, a heat discussion among supporters and opponents was aroused. This paper has no intention to explore any reasons behind, but only to apply critical thinking [2-3] to analyze various thinking fallacies committed by the letter.

\section{MAJOR THINKING FALLACIES IN THE OPEN LETTER}

\subsection{Inadequate Fundamental Facts}

Liaoning Daily editors and its open letter keep emphasizing that its arguments were based on the 130-thousand-word notes they collected in actual lectures. However, the letter never mentioned any details about those lecture notes. For example, what was the topic of the lecture, what was the context of the comment, in which university, and etc,. Without fundamental facts to their reasoning, the letter's arguments would not sound persuasive.

Additionally, the letter also made several obvious mistakes on key time nodes.

According to the 'editor's notes' in Liaoning Daily and the main body of the letter, the plan was originated from a comment by a web user, KiKo, under Liaoning Daily's official Wechat's opinion poll named 'how does classes in China's university look like'. The poll started on October 21 , 2014, and the special topic started by the letter on November 14, 2014. There are only 25 days in between, even less than a month.

However, the 'editor's notes' in Liaoning Daily claimed that they had investigated for more than two months in several universities inside and outside the province. This contradicted the previous calculated time frame, regardless whether the half-month of 'sitting in more than a hundred lectures in universities in Shenyang, Beijing, Shanghai, Wuhan and Guangzhou' are included.

The letter omitted the basic facts on which it should build it argument and miscalculated the time duration facts. It would be unsurprising that readers 
would therefore doubt on the editors' attitude, professional level and factual basis, and further question the credibility of the letter's conclusion. The following sections will briefly analyze some main thinking fallacies which would undermine the letter's credibility.

\subsection{Statistic Trap}

The letter used statistics three times. This section will analyze all of them and point out the thinking fallacies of each.

The first statistic appeared in the following paragraph:

\section{China now becomes the database for negative cases in university lectures. Is it just an isolated instance, or is it already a pervasive phenomenon? We used new media approach to investigate and found more than $80 \%$ of college students saying that they had experienced "querulous" teachers. Such disgrace to the country was even unbearable to students. The phenomenon was more common in philosophy and social science lectures including law, administrative management and economics.}

Such investigation has obvious problems in the investigation design as well as data representation.

First, the letter did not introduce what the new media approach is. If the investigation was an online survey, then participants would usually be those who were interested in the topic. Since the range of the sample was narrow, the survey result would suffer selection bias and hence invalid. For instance, the Durex Company's global sex survey in 2004 reported that globally people had had 10.3 sexual partners on average, while people in China had 19.3 partners on average, the highest of all nations. The survey method used by Durex was online survey, which belongs to the new media approach. However its conclusion was obviously biased. The survey approach problem was further confirmed in Druex's survey in 2005, where the average sexual partner number reduced greatly to 3.1 for people in China [5]. The huge differences in only one year's time can only be reasonably explained by the fallacies in its research method.

Secondly, the letter did not mention how many people participated in the survey. A ratio without a total number is a typical statistic trap, in addition to have certain demagogic deception value, which is therefore unpersuasive.

Hence, statement that 'China now become the database for negative cases in university classes could not be supported by the investigation.

The second paragraph that contained statistics was to provide the source for the 130-thousand-word lecture notes:
To research on the issue on lecturers, we chose to become students again. Reporters from Liaoning Daily went to all directions to more than twenty universities in five cities including Beijing, Shanghai, Guangzhou, Wuhan and Shenyang, sat in more than a hundred lectures in half a month.

This paper will not discuss whether the selected five cities matches with the term 'all directions', but the distribution and coverage of these cities. All these cities are big cities in China. None of the small or middle sized cities were involved. Therefore, the selected cities could not represent the whole country. As to the coverage, according to the Ministry of Education, there were 2442 colleges and universities in 2012, 1145 of them were universities. Liaoning Daily's investigation had a coverage rate of $0.819 \%$ if using the first datum and $1.75 \%$ of the second. Such coverage was obviously too low.

Therefore, the representative sample of the investigation is seriously insufficient. It is impossible to convincingly draw some general useful conclusions from this investigation.

The investigation of the third paragraph that shows the working people complaining is as follows:

\section{Investigation Shows, 90\% of the working people complain every day, People's lives better and better, but complaints are more and more.}

Which agency made this survey? How the agency's credit? When published? How many people were surveyed? How the survey was made? The open letter had not mentioned. As a result, the result is unbelievable.

If the result is believable, facing as much as ninety percent of people every day in complaining, we should not adopt the ostrich policy, turned a blind eye to it, should have correct attitude, and take it seriously., We should further investigate what cause of as much as ninety percent of people every day in complaining is, then effectively resolve the cause. Complains are not always correct, seriously and correctly treating complaints is always right. So, the society will be harmony and more beautiful.

\subsection{Hasty Generalization}

At least, samples of the first two statistics in the above three statistics are too small, their data distributions are narrow, the conclusions made from these kind of statistics committed statistical fallacy, and also committed hasty generalization fallacy. We will point another example of hasty generalization fallacy in this section.

When we put these questions to consult the teachers, whether doctoral supervisor, professors or lecturer, teaching assistant, the 
mainstream answers are distinctively: can't do that! But there exist some teachers who query as follows:

"Teacher has the right to decide how to speak in class. Can you interfere with my academic "freedom?

"Avoiding discussion of real society issues, how to teach in classes?"

"The party and the government should be good at listening to people's complaining and cynical remark, otherwise, how to alleviate social pressure?"

An ordinary person can query such questions, but dear teachers, because of the nobility Of your profession and the solemn and particularity of university classroom, please do not talk about China like that.

Since the mainstream of answer, which is the answer of most of teachers, is not to show "the three lacking" in university classes, that is to say there are just a few teachers having "three lacks" problems, your open letter to university philosophy and social science teachers is take the whole of university philosophy and social science teachers as object, which committed hasty generalization fallacy. We should treat a group mainly with their mainstream, rather than their tributaries. For example, Although news media people committed a series of crimes such as He rundong mismatches, Chen yongzhou event, Guo zhengxi and Tian Liwu events, Rui chenggang and Li yong event and news fraud in the 21 st century network only since 2013, we cannot conclude that all the news media people is a criminal gang based on the series of crime cases committed by some of the news media people; otherwise, we will commit hasty generalization fallacy.

\subsection{Wishful Thinking}

The open letter said as follows:

Students all belongs to the sunflower family, who are accustomed to turn toward the teacher. If the teacher standing on the platform has a bright mind, the students taught by the teacher are all active and bright. People in the society are all bright builders, the country must have a bright future.

The above text is of three universal assertions, only need to be respectively given a counterexample, the three assertions will be denied respectively. The first counterexample is the student whose web name is Kiko in the open letter. By the "web comments", the student has shown the spirit of dare to doubt about his teacher, who don't belong to the sunflower family, are not accustomed to turn toward his teacher. Secondly, Ma Jiajue is not a student of bright mentality, Yao Jiaxin is also not a student of bright mentality. In all the teachers of the two students, not all the teacher have not bright mentality? Thirdly, the society is a big world, is very complex, has builders, also has saboteur, and of course also has those who have nothing to do. Even in the builders, not all the builders are necessarily a "bright builders", in which some people are corrupt "dark builders" in the name of building. According to the assertion in the open letter, due to the existence of some corrupt "dark builders", our China will not have a bright future. Therefore, for the sake of our China can have a bright future, it is necessary to turn each dark builder into a bright builder. How can we do it? Maybe there are many methods, however, the first step of all the methods is to point out dark builders, and criticize their wrong words and deeds. So, the problem must be pointed out, criticism must be conducted.

In the above segment, the Liaoning daily consecutively committed "wishful thinking" fallacy.

\subsection{Straw Man}

Teachers give negative examples of China in class. Their purpose is to explain the corresponding principles and problem solutions. The open letter considers giving negative examples of China in classes as complaining or "the object of criticism must be China", which is deliberately distorted, if not innocent misunderstood, in a word, is made "straw man" thinking fallacy.

Even if is to complain, don't have to make a fuss, also not necessarily a bad thing. On the one hand, as an open letter pointed out, "complaining is a human instinct", since being the case, you don't have to make a fuss; Otherwise, is contrary to human nature? On the other hand, we should all know, complains is not always correct, perhaps often may be wrong because of extreme and one-sided. However, complains are not always correct, seriously treating complaints, correctly analyzing causes of complaints and creatively resolve complaints, are always right. Comrade MAO zedong taught us that "people complaining, have opinions, suggests that there is something wrong with our policy and work. Don't hear the crowd, especially a little sharp comments, go to pursue, to file a case, to hit to suppress. It is actually a sign of weakness, is usually the sign of neurasthenia. Anyway we communists do not make the opposite situation with the people." Perhaps the Liaoning daily have forgotten the teachings of Chairman Mao's; otherwise, how could they require "stop complaining"? 


\subsection{Contradiction}

When it comes to "stop whining", the open letter also committed "self contradictory" thinking fallacy in the "stop complaining". The open letter takes teacher criticizing China negative phenomena as complain, and then suggest "stop complaining to take an aggressive attitude to think about the light".

According to the thinking mode in which the open letter takes "criticism" as "complain", we also can take the open letter criticizing the university philosophy social science teachers as "complain", then suggest that the Liaoning daily "stop complaining to take a aggressive attitude to think about the light".

Moreover, how can the teachers know the negative phenomena of China? It is because of a large number of reports made by news medium such as Liaoning daily. Here comes a contradiction, news medium such as Liaoning daily can report a lot of negative phenomena of China, meanwhile, our teachers can not mention negative phenomena of China in class.

If Liaoning daily don't think they committed "self-contradictory" thinking fallacy, then Liaoning daily have committed a "double standard" thinking fallacy.

\subsection{Appeal to Authority}

The open letter said as follows:

\section{A litterateur said, education is the greatest living principles of a nation, is the only one means to reduce the number of evil and increase in the number of the good in all society.}

Firstly, the above text committed thinking fallacy of "appeal to authority". Secondly, don't know is intentionally or unintentionally, it didn't disclose who this litterateur is. Although the open letter keeps secret, we still know the litterateur is Balzac of France, and, also know that Balzac is a famous litterateur of critical realism. His criticism of the social system is very deep, he regarded education is to cultivate people's critical spirit. The open letter's authors maybe don't correctly understand the real meaning of "education" called by Balzac, of course, there is also another possibility, that is, the authors is actually know the "spirit of criticism" contained in Balzac's "education", but Deliberately not to mention the name of Balzac, lest that the reader is reminded by the identity of the "critical realism writer Balzac, so that the authors can induce the readers to understand the meaning of the word "education" only in a literal and superficial way.

In fact, even with the literal meaning, "to reduce the number of evil and increase in the number of the good" does not mean that do not allow criticism and criticism of China negative phenomena, because whether the amount of criticism or praise the number will not change the kind of evil. The letter here not only committed thinking fallacy of "appeal to authority", but also committed "irrelevant" thinking fallacy, and at the same time also committed "misinterpretation" thinking fallacy.

\section{CONCLUSION}

In conclusion, the open letter not only have defects and errors in fundamental facts related with their argument foundation, but also have a lot of thinking fallacies, in which many of those thinking fallacies are very low. The existence of these thinking fallacies is enough to completely eliminate credibility of the open letters. Thus, good motivation doesn't necessarily bring good results, but also need to have solid basic skills. For the media reporters, it is far from enough to only have brilliant pen, should also have the objective, rational and tolerant spirit accomplishment and justice, integrity and logical thinking quality.

\section{REFERENCES}

[1] Liaoning Daily editorial office, Teachers, please do not talk about China like that: An open letter to philosophy and social science teachers, November 15, 2014.

[2] M. Neil Browne, Stuart M. Keeley, translated by Zhao Yufang, Asking The Right Questions: A Guide to Critical Thinking (10th Edition), China Machine Press, Published in December 2012.

[3] Richard Paul, Linda elder, translated by Hou yubo, Critical Thinking Tools for taking change for your learning and your life, 3rd Edition, China Machine Pres, published in December 2012.

[4] Christophe Barratier, Les choristes, produced by the French EMI Studios, On March 17, 2004, officially released in France.

[5] Chang chen, Durex sex survey: China's per capita sexual partners fell from 19.3 to 3.1 ,

http://news.163.com/05/1130/16/23QO60SH0001122B.html 